\title{
Morphological characterization of the proventriculus of Gryllus assimilis Fabricius (Orthoptera, Gryllidae)
}

\author{
Carmem S. Fontanetti ${ }^{1}$ \\ Edison Zefa ${ }^{1,2}$
}

\begin{abstract}
The proventriculus morphology of the cricket Gryllus assimilis Fabricius, 1775 is described using scanning electron microscopy and the correlation of this structure with the feeding habits briefly considered.

KEY WORDS. Orthoptera, Gryllidae, Gryllus, proventriculus
\end{abstract}

In general, the digestive tube of the insects can be divided into three areas: the foregut or stomodeum, the midgut or ventriculus and the hindgut or proctodeum. Its morphological diversity has lead several authors to use it as a systematic and phylogenetic character in several groups (MORTINER 1965; SINGH \& JUDD 1966; GRANT \& RENTZ 1967; DELIGNE 1971; BORDAS 1896, 1898).

The foregut is made up of the pharynx, esophagus, crop, and proventriculus or gizzard. The last structure is of great taxonomic interest, since it is intimately associated with the insect feeding habit, that can be highly species specific.

The proventriculus is a transition area between the foregut and midgut and like the remainder of the anterior intestine, has an ectodermal origin and possesses a sclerotized intima. It presents all the stages of development, varying from a simple valve formed by fine cuticle, to a strong muscular organ, armed with spines and teeth, having as a main function the grinding of food.

Many studies have been accomplished to recognize relationships between the morphology of the proventriculus and the alimentary habits of insects. LEBRUN (1985) and LEBRUN \& LEQUET (1985), showed that the proventriculus of termites that feed on wood has a cuticular armor formed by strong teeth and sclerotized plates, while those that feed on decomposed wood do not present teeth and the plates are less developed. In the humus eating termites, the armor of the proventriculus is weak and only small plates are present. GIBBS (1967) also observed variations in the structure of the proventriculus of nine species of Trichoptera, demonstrating that the proventriculus can perform in the grinding or filtering of food.

JUDD (1948) studied comparatively several families of ensiferans Orthoptera and elaborated a key to identify the families and orders, using the proventriculus and the gastric caecum as characters of taxonomic value.

1) Departamento de Biologia, Instituto de Biociências, Universidade Estadual Paulista. 13506-900 Rio Claro, São Paulo, Brazil. E-mail: fontanet@rc.unesp.br

2) CNPq fellow. 
BLAND \& RENTZ (1991) studied 17 species of Australian grilacridids, discussing the use of the proventriculus as a character and more briefly, the correlations between the structure of the proventriculus and the alimentary habits of the species. Here in we describe the morphology of the proventriculus of Gryllus assimilis Fabricius, 1775 is described.

The results of this study may eventually be used as a taxonomic resource for the genus Gryllus Linnaeus, 1758, which includes a great number of cosmopolitan and sibling species, where the recognition through their external morphology is difficult.

\section{MATERIAL AND METHODS}

Seven adult males and six females were collected from grassland and lawns by E. Zefa at Universidade Estadual Paulista, Campus of Rio Claro, São Paulo, in the months of March and April, 1998. The specimens were dissected in physiological solution and the digestive tubes were removed. The proventriculi were fixed in a solution of KARNOWSKY (1965) and processed for observation under the scanning electron microscope. Diagram of the alimentary canal was obtained with aid of a camera lucida coupled to a stereomicroscope.

\section{RESULTS AND DISCUSSION}

The digestive tube, especially the proventriculi, of several adult male and female specimens of $G$. assimilis was compared and no difference was observed between the two sexes. It is composed of a short pharynx, that opens into the buccal cavity, proceeded by the esophagus, the crop and the proventriculus; this segment form the foregut. The midgut or ventriculus, presents a pair of large and voluminous gastric ceca that line the whole proventriculus. The hindgut is then observed, ending in the rectum, which opens into the anus. Numerous Malpighian tubes are observed inserted into the transition between midgut and hindgut (Fig. 1).

The proventriculus measures approximately $2.5 \mathrm{~mm}$ in length and $2.0 \mathrm{~mm}$ in diameter and presents a flat wall in the external part. Internally, the proventriculus presents six rows formed by groups of sclerotized appendices united to each other by sclerotized partitions (Fig. 2A). Twelve sclerotized appendices were observed composing each row. The sclerotized appendix (Fig. 2B,C) is formed by a central projection, the medium tooth and two lateral expansions, the lateral teeth. The medium tooth presents, on average, seven denticles facing the lumen, called medium denticles (Fig. 2C). Two projections extend from the medium tooth in a lateral direction; these are called lateral teeth. They possess several denticles on their apical face, called lateral denticles (Figs 2C, 3A,B,D). Both the medium denticles and the lateral ones have a rounded apex. The apical projection of the lateral tooth partially surrounds the basal projection (empty arrows in figures 3A, B). The latter is therefore located more internally (empty arrows in figures 3C,D). The apical projection of the lateral tooth is formed by two semicircular rows made up, on average, of seven denticles (Figs 3C,D). On either side of the rows of sclerotized appendices, small expansions can be observed, called sclerotized lobes (Figs 2A,B, $3 \mathrm{C}$ ), with setose in their more internal portion (full arrows in figures $2 \mathrm{~B}, \mathrm{C}, 3 \mathrm{~B}, \mathrm{C}, \mathrm{D}$ ). These structures correspond to the inner barbed lobes mentioned by JUDD (1948). 

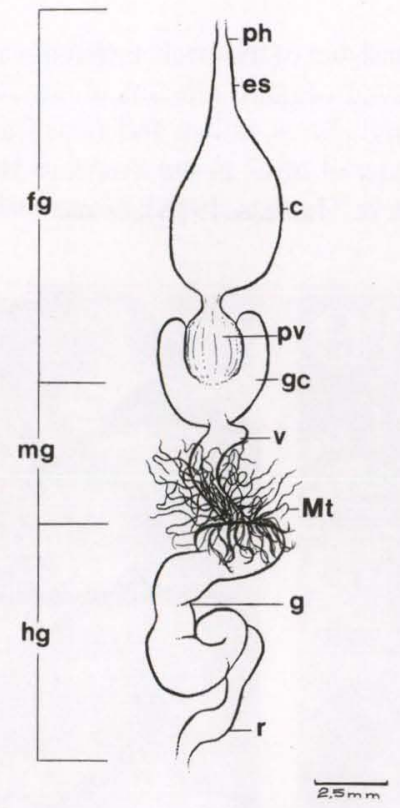

Fig. 1. General outline of the digestive tube of Gryllus assimilis. (c) Crop, (es) esophagus, (fg) foregut, (g) gut, (gc) gastric caecum, (hg) hindgut, (mg) midgut, (Mt) Malpighian tubes, (p) pylorus, ( $\mathrm{ph}$ ) pharynx, ( $\mathrm{pv}$ ) proventriculus, (v) ventriculus.

Comparing our data with those of JUDD (1948), the proventriculus of $G$. assimilis resembles that of other species namely Oecanthus nigricornis Walker, 1869, Neoxabea bipunctata DeGeer, 1773 (Oecanthidae), Falcicula hebardi Rehn, 1903, Anaxipha exigua Say, 1825, Phyllopalpus pulchellus Uhler, 1864, Cyrtoxipha columbiana Caudell, 1907 (Trigonidiidae), Hapithus brevipennis Saussure, 1897, Orocharis saltator Uhler, 1864, Tafalisca lurida Walker, 1869 (Eneopteridae), Nemobius fasciatus DeGeer, 1773 (Nemobiidae) and Cycloptilum squamosum Scudder, 1868 (Mogoplistidae). In these species, the main differences were the form of the medium tooth and denticles, and the lateral teeth.

For the family Gryllidae, JUDD (1948) studied Gryllus domesticus Linnaeus, 1758, Gryllus assimilis Fabricius, 1775 and Anurogryllus muticus DeGeer, 1773. Although he mentioned $G$. assimilis, he did not present a description of its proventriculus.

BLAND \& RENTZ (1991), compared several species of Australian grilacridids, and suggested that in the herbivorous ones predominate long lateral denticles, when compared to predatory ones. Moreover, they comment that the internal structure of the proventriculus is different among genera.

The morphology of the proventriculus observed in G. assimilis, agrees with the observations of BLAND \& RENTZ (1991), about the correlation between proventricular morphology and alimentary habits of orthopteran species. According authors, species preferentially herbivorous shows long teeth and lateral denticles, like G. assimilis. 
Although, the natural diet of the crickets that live in the soil is little understood, GANGWERE (1961) observed organic remains, dicotyledonous leaves, and smaller quantities of insect remains, spores, pollen and grass fragments in the analysis of the crop content and fecal material of $G$. pennsylvanicus Burmeister, 1838 and Allonemobius allardi (Alexander \& Thomas, 1958); G. assimilis probably has a similar diet to the ones.
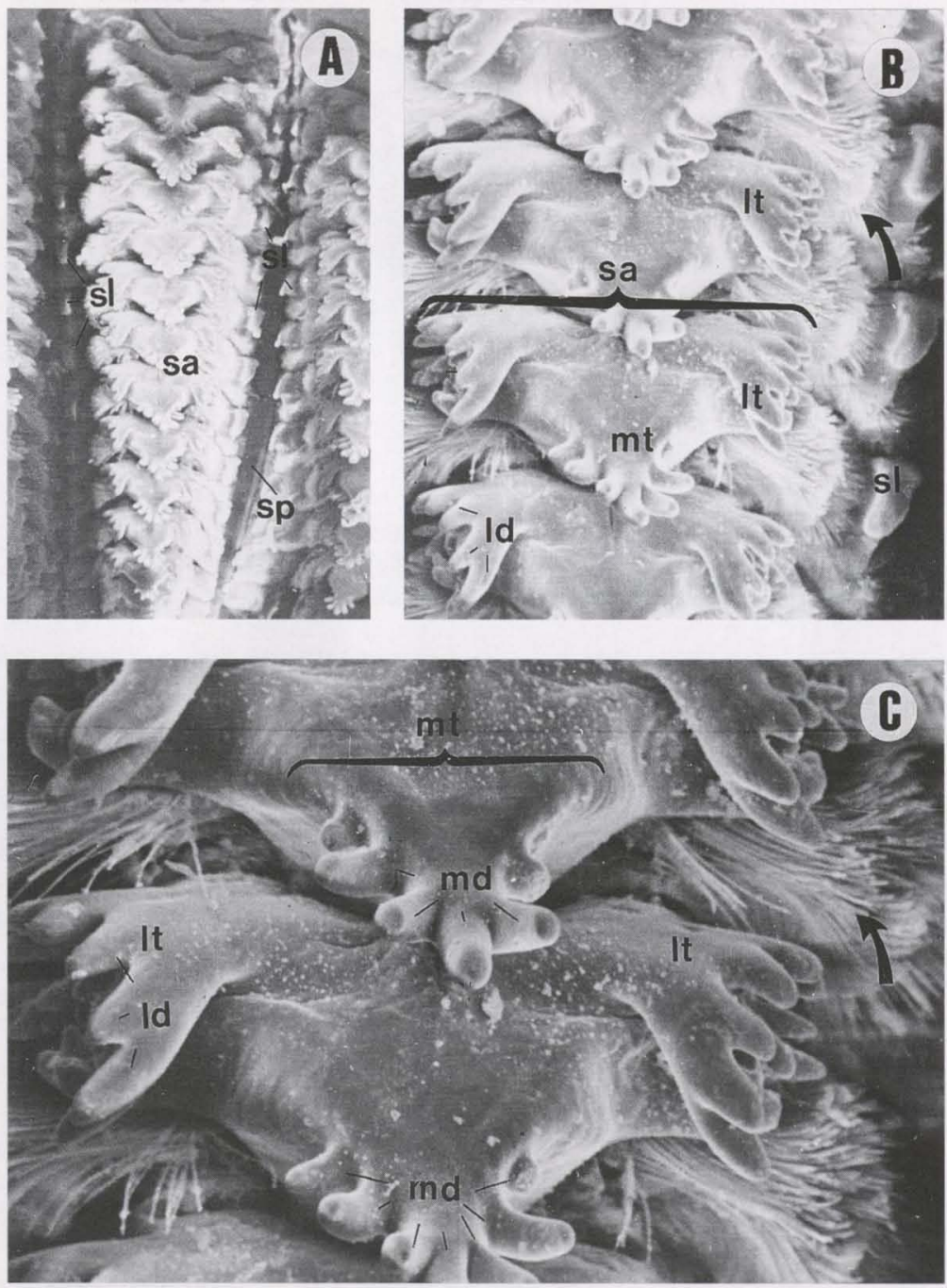

Fig. 2. Internal view of the proventriculus of $G$. assimilis. (A) General view of a row of sclerotized appendices separated by the sclerotized septa; $(B-C)$ details of the sclerotized appendices. (Id) Lateral denticles, (It) lateral teeth, (md) medium denticles, (mt) medium tooth, (sa) sclerotized apendix, (sl) sclerotized lobes, (sp) sclerotized partition, (full arrows indicate setose of the sclerotized lobes (inner barbated lobes, according to JUDD 1948). 

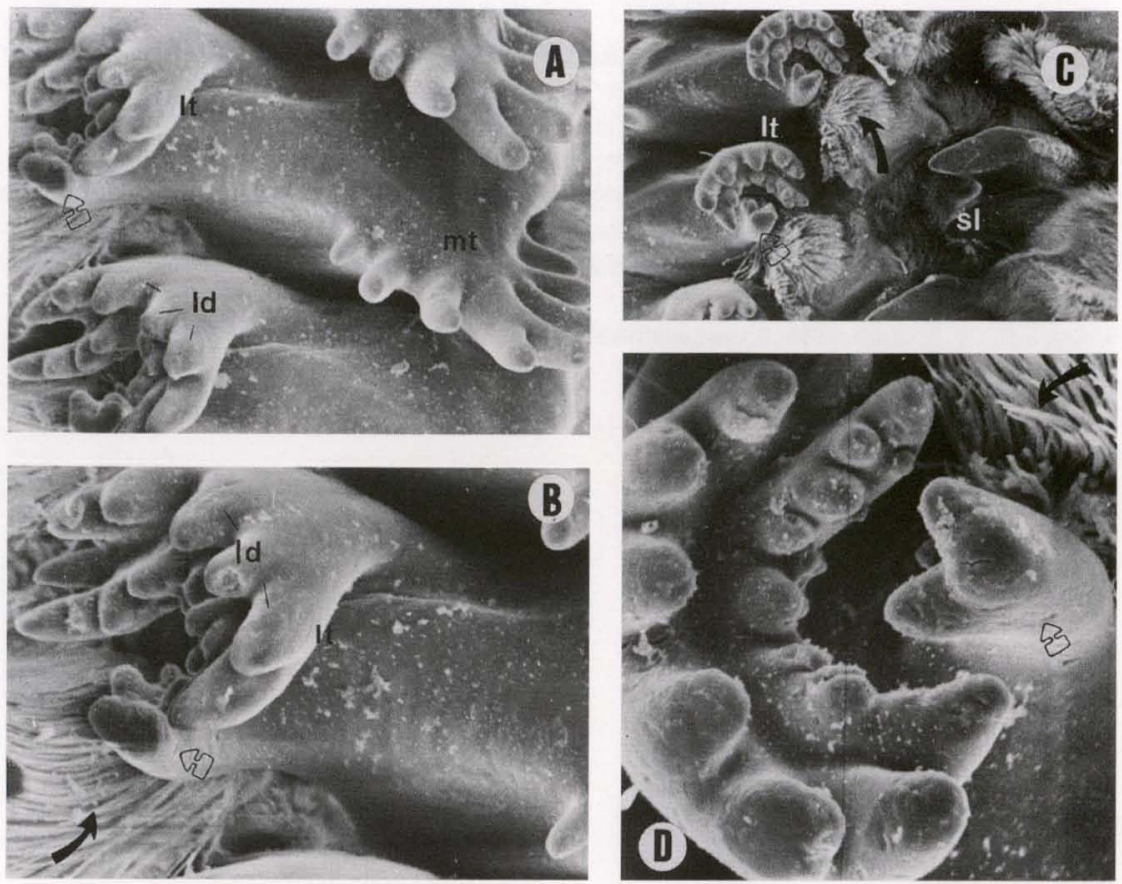

Fig. 3. Proventriculus of $G$. assimilis. (A-B) Front details of the lateral teeth; (C) Lateral view between two rows; (D) detail of the lateral denticles. (Id) Lateral denticles, (It) lateral tooth, (mt) medium tooth, (sl) sclerotized lobe. Full arrows indicate the setose sclerotized lobes; empty arrows indicate the internal part of the lateral tooth.

ACKNOWLEDGMENTS. We especially thank Dr. Alejo Mesa for the incentive, Mônika Iamonti, Antônio Yabuki and Wenilton Daltro for the technical help and CNPq and FAPESP for the financial support.

\section{REFERENCES}

BLAND, R.G.; D.C.F. RENTZ. 1991. Studies in australian Gryllacrididae: the proventriculus as a taxonomic character. Invertebr. Taxon. 5: 443-455.

BoRDAS, L. 1896. Etude de l'armature masticatrice du gésier chez les Blattidae et les Gryllidae. Compt. Rend. Nat. Acad. Sci. Fr. 123: 271-273.

- 1898. L'appareil digestif des orthopterès et son importance pour la classification des orthoptères. Ann. Sci. nat., Zool., Paris, 5: 1-192.

Deligne, J. 1971. Morphologie du tube digestif et affinités systématiques du genre Tuberculitermes. Rev. Zool. Bot. Afr. 84 (1-2): 184-191.

GANGWERE, S.K. 1961. A monograph on food selection in Orthoptera. Trans. Amer. Entomol. Soc. 87: 67-230.

GiBBS, D.G. 1967. The proventriculus of some trichopterous larvae. Jour. Zool. London 152: 245-256.

GRANT JR., H.J.; D.C. RENTZ. 1967. A biosystematic review of the family Tanaoceridae including a comparative study of the proventriculus. Pan-Pacific Ent. 43 (1): 65-74.

JUDD, W.W. 1948. A comparative study of the proventriculus of orthopteroid insects with reference to its use in taxonomy. Can. Jour. Research. 26 (D): 93-161. 
KARNOWSKY, M.J. 1965. A formal dehyde-glutaraldehyde fixative at high osmolarity for use in electron microscopy. Jour. Cell Biol. 11: 137-140.

LeBrun, D. 1985. Structures digestives et régimes alimentaires des Termites. Actes Coll. Insects Soc., Diepenbeek, 2: 43-44.

LeBrun, D.; A. LeQuet. 1985. Relations entre le régimes alimentaires et la structure du gésier des termites. Bull. Soc. Sc. Nat. Quest France, n.s., 7 (3): 126-139.

MORTIMER, T.J. 1965. The alimentary canal of some adult Lepidoptera and Trichoptera. Trans. r. ent. Soc. London 117 (3): 67-93.

STNGH, S.B.; W.W. JUDD. 1966. A comparative study of the alimentary canal of adult calyptrate Diptera. Proc. Entomol. Soc. Ontario 96: 29-80.

Recebido em 15.IV.1999; aceito em 08.II.2000. 